\title{
Abstracts from the literature
}

\begin{abstract}
AIDS associated with transfusions
Of 2157 patients with the acquired immunodeficiency syndrome (AIDS) whose cases were reported to the Centers for Disease Control by August 22, 1983, 64 (three per cent) with AIDS and Pneumocyscis carinii pneumonia had no recognized risk factors for AIDS. Eighteen of these (28 per cent) had received blood components within five years before the onset of illness. These patients with transfusion-associated AIDS were more likely to be white $(p=0.0013)$ than other patients with no known risk factors. They had received blood 15 to 57 months (median 27.5) before the diagnosis of AIDS, from 2 to 48 donors (median, 14). At least one high-risk donor was identified by interview or T-cell-subset analysis in each of the seven cases in which investigation of the donors was complete; five of the six high-risk donors identified during interview also had low T-cell helper/suppressor ratios, and four had generalized lymphadenopathy according to bistory or examination. These findings strengthen the evidence that AIDS may be transmitted in blood. (Curran JW, Lawrence DN, Jaffe $H$ et al. Acquired immunodeficiency syndrome (ADDS) associated with transfusions. N Engl J Med 1984; 310:69-75. See also Bove JR, TransfusionAssociated AIDS - A cause for concern (Editorial). N Engl J Med 1984; 310: $115-6)$
\end{abstract}

\section{Non-depolarizing muscle relaxants in pre- curarization}

Five different non-depolarizing muscle relaxants and a control solution of saline were studied as precurarization agents. Two hundred and twentytwo surgical patients (ASA physical status I-II) were allocated in a double-blind fashion to one of the following groups: d-tubocurarine $0.05 \mathrm{mg} \cdot \mathrm{kg}^{-1}$, alcuronium $0.03 \mathrm{mg} \cdot \mathrm{kg}^{-1}$, pancuronium 0.01 $\mathrm{mg} \cdot \mathrm{kg}^{-1}$, gallamine $0.25 \mathrm{mg} \cdot \mathrm{kg}^{-1}$, ORG NC-45 (vecuronium) $0.01 \mathrm{mg}^{-\mathrm{kg}^{-1}}$ and saline solution $0.005 \mathrm{mg} \cdot \mathrm{kg}^{-1}$. Pretreatment was performed $4 \mathrm{~min}$ before administering a $1.5 \mathrm{mg} \cdot \mathrm{kg}^{-1}$ bolus of succinylcholine ( $\mathrm{SCh}$ ). Fasciculations, intubation conditions, duration of neuromuscular blockade after
SCh, serum potassium changes and postoperative myalgias (in 60 patients) were recorded. All the drugs studied prevented fasciculations significantly $(p<0.05)$ morc than in the control group d-turbocurarine and alcuronium were superior to the others in this respect. Intubation conditions were best in the control and pancuronium groups, but there was no significant difference between the pancuronium and d-tubocurarine or between the d-tubocurarine and alcuronium groups. Pancuronium pretreatment prolonged the SCh block significantly, whereas other agents shortened the duration of the SCh block. The antagonism of the SCb block apparently also affected incubation conditions, although intubation remained satisfactory. A statistically significant rise in serum potassium level was measured only in the control and pancuronium groups. In the control and pancuronium groups, four patients out of ten had postoperative myalgias, whereas in the other groups only one or none out of ten had them $(0 / 10$ vs, $4 / 10 ; 0.10>p>0.05)$. In conclusion, d-tubocurarine and alcuronium seem to have advantages over pancuronium, ORG $\mathrm{NC}-45$ and gallamine for precurarization. (Erkola $O$. Salvenpera A, Kuoppamäki R. Acta Anaesthesiol Scand 1983; 27: 427-32)

\section{Diaphragm dysfunction following surgery}

The effects of upper abdominal surgery on diaphragmatic function were studied in five patients. During quiet tidal breathing, the volume displacement of the abdomen within the tidal volume $(\mathrm{Vab} / \mathrm{Vt})$ and the ratio of abdominal and transdiaphragmatic pressure changes ( $\Delta \mathrm{Pab} / \Delta \mathrm{Pdi}$ ), taken as an index of the diaphragmatic contribution to the breathing process, decreased significantly on the first postoperative day; in two patients, a cephalad paradoxical motion of the diaphragm during inspiration was observed. Diaphragmatic dysfunction also occurred during maximal inspiratory efforts as shown by the significant fall in maximal static transdiaphragmatic pressure ( Pdi $_{\text {max }}$ ) and cephalocaudal diaphragmatic displacement on the first and third postoperative days. On the first postoperative 
day, opiate epidural analgesia did not modify $\mathrm{Vab} / \mathrm{VT}, \Delta \mathrm{Pab} / \Delta \mathrm{Pdi}$ and $\mathrm{Pdi}_{\max }$. These parameters spontaneously returned towards control values on the seventh postoperative day. The authors conclude that upper abdominal surgery induces a marked diaphragmatic dysfunction lasting about one week and that it is not suppressed by postoperative pain relief. The mechanism of this dysfunction remains to be determined. It may be the main cause of the postoperative pulmonary restrictive pattem. (Simonneau $G$, Vivien A, Sartene $R$ es al. Diaphragm dysfunction induced by upper abdominal surgery. Am Rev Respir Dis 1983; 128: 899-903)

\section{Air embolism during total hip replacement}

In order to demonstrate the presence of air embolism during total hip replacement surgery, six patients chosen at random were examined with an ultrasound probe placed over the right atrium. In five patients, the characteristic double cardiac sound coming from the ultrasound probe changed into an irregular rattling sound as the femoral cement started generating its maximum hardening heat. In two patients this change was also heard simultaneously with the insertion of the femoral prosthesis. In four patients in whom catheters were placed in the right atrium it was possible to aspirate a maximum of $3 \mathrm{ml}$ of air from the right atrium. During the cementation of the acetabulum, no change in the signal coming from the ultrasound probe was registered. It is probable that air is formed in the venous system during the insertion and cementation of a femoral prosthesis. The resulting air embolism is presumed to be the cause of the major, but generally very brief impaiment of the central circulation and the lungs seen during hip arthroplasty. In the case of patients undergoing anaesthesia with $\mathrm{N}_{2} \mathrm{O}$, the $\mathrm{N}_{2} \mathrm{O}$ should be removed before the cementation. It is also suggested that perhaps the right atrium should be catheterised, in order to reduce the risk of this complication. (Andersen KH. Air aspirated from the venous system during total hip replacement. Anaesthesia $1983 ; 38: 1175-8$ )

\section{Incidence of aspiration in intubated infants and children}

A prospective study is reported which examines the incidence of aspiration in 50 infants and children intubated with a noncuffed endotracheal tube in a multidisciplinary paediatric PICU. Aspiration was assessed by applying Evans blue dye on the tongue and searching for the dye during suctioning, in the endotracheal aspirate. Twenty-nine (58 per cent) were medical patients and 21 (42 per cent) surgical; ages ranged between 25 hours and four years (mean 18.5 months). Respiratory failure was the major indication for endotracheal intubation and mechanical ventilation in 26 ( 52 per cent) of the patients, hyperventilation for increased intracranial pressure in 12 (24 per cent), congestive heart failure in eight (16 per cent), and protection of the airway in deeply comatose patients in four (eight per cent). The patients remained intubated from 18 hours to 12 days (mean 70.4 hours). Evidence of aspiration was found in eight (16 per cent) of the patients, accompanied by changes in the chest $x$-ray in five (63 per cent) patients and a significant fall in $\mathrm{PO}_{2}$ in three ( 37 per cent). Aspiration was not significantly affected by the presence of a nasogastric tube, level of consciousness or ventilator setting. The authors conclude that noncuffed endotracheal tubes of proper size that adequately seal the trachea effectively prevent clinically significant aspiration in endotracheally intubated infants and children. (Goirein KJ, Azaria JJTR, Gornstein A. Incidence of aspiration in endotracheally intubated infants and children. Crit Care Med 1984; 12:19-21)

\section{Postoperative IPPB}

Thirty patients undergoing elective cholecystectomy were randomly assigned to two groups. Fifteen patients received postoperative intermittent positive pressure breathing (IPPB) for four days together with physiotherapy while the other $15 \mathrm{had}$ the same postoperative care but without IPPB. Vital capacity (VC), functional residual capacity (FRC) and $\mathrm{PaCO}_{2}$ wete measured preoperatively and on days $0,1,3$ and 5 postoperatively. The incidence of postoperative pulmonary complications utilizing chest $x$-ray films, sputum analysis, temperature, and clinical assessment was determined. Both groups had significant deterioration in pulmonary function but did not differ except for a greater depression in VC in the IPPB group. In patients receiving postoperative physiotherapy, the addition of IPPB did not usually result in improved pulmonary function. (Ali $J$, Serrette $C$, Wood $L D H$, Anthonisen NR. Effect of postoperative intermittent positive pressure breathing on lung function. Chest $1984 ; 85 ; 192-6$ ) 